\title{
Effects of human culture among AEC professionals towards adaptation of collaborative technology in industrialized project delivery
}

\begin{abstract}
Collaborative technology would change how AEC professionals instill their work culture when using BIM-enabled visualization applications during industrialized projects. This desktop study is to identify the base line communication preferences that can help building stakeholders to prepare themselves to export their professional services in delivering transdisciplinary global project implementation. The study found AEC's professional culture, method of knowledge transfer, and educational programs could affect several dimensions of their beliefs and values in ways of delivering global transdisciplinary projects. This study is limited to understanding and documenting the effects of human factors during the integrated project delivery phase. These contributions would support developing countries' professionals to collaborate effectively with developed countries' professionals. Future development of supportive communication systems in integrated design studio education programs is recommended to prepare future Malaysian AEC transdisciplinary global practices.
\end{abstract}

